\title{
AC 2012-4683: DESIGNING AND BUILDING COMPETITIVE HYBRID ELECTRIC RACING VEHICLES AS A VALUED TEACHING AND LEARN- ING METHOD FOR UNDERGRADUATE ENGINEERING STUDENTS: A TWO-YEAR REVIEW WITH A PROJECTION OF FUTURE PLANS
}

\section{Dr. Robert W. Fletcher, Lawrence Technological University}

Robert W. Fletcher joined the faculty of the Mechanical Engineering Department at Lawrence Technological University in the summer of 2003, after several years of continuous industrial research, product development and manufacturing experience. Fletcher earned his bachelor's of science degree in chemical engineering from the University of Washington, in Seattle, Wash., a master's of engineering in manufacturing systems from Lawrence Technological University, in Southfield, Mich., and master's of science and $\mathrm{Ph} . \mathrm{D}$. degrees in chemical engineering focusing on electrochemical engineering, both from the University of Michigan, in Ann Arbor. He teaches a number of alternative energy courses and is leading LTU's efforts to establish a full energy engineering program that addresses both alternative and renewable energy systems, as well as energy conservation and optimization of traditional energy systems. He also is the Director of the Alternative Energy program at Lawrence Tech. 


\title{
Designing and building competitive hybrid electric racing vehicles as a valued teaching and learning method for undergraduate engineering students; a two year review with a projection of future plans
}

\begin{abstract}
Hybrid electric vehicles with on-board electric energy storage, such as advanced lithium-ion batteries, are a rapidly developing area in the automotive industry. Engineering students with knowledge and experience in this field are in high demand in automotive companies. Lawrence Technological University was involved in the design, development, and building of two series hybrid electric competitive racing vehicles, and has now built a third vehicle in the $2011-2012$ academic year. These student-run team's hybrid racing vehicles compete in the Formula Hybrid $^{\mathrm{TM}}$ competition, typically held during the first week of May in at the New Hampshire Motor Speedway in Louden, New Hampshire. The challenges and benefits of the more familiar Formula $\mathrm{SAE}^{\mathrm{TM}}$ competition are well documented and are now a common element of most mechanical engineering schools in both the US and around the globe. The Formula Hybrid ${ }^{\mathrm{TM}}$ competition, however, is a much smaller competition involving fewer entrants with typically around 25 teams in actual attendance at the competition. From a design and build perspective the hybrid competition involves a much broader field of skill sets from students to deliver a successfully operating vehicle. While there are common design elements to the more well-known Formula $\mathrm{SAE}^{\mathrm{TM}}$ car, the hybrid car requires more electrical and computer interface design aspects to the overall project. These are unique to hybrid vehicles. Important basic questions such as should the vehicle be a series or parallel power system design will have a dramatic impact on how a team proceeds. These unique design features and alternative energy aspects of hybrid vehicles make this a challenging, ideal real-world senior design and university-based student club project. As a result there are valuable teaching and learning opportunities for students, and faculty, in this rapidly developing future growth area of the automotive field. Lawrence Tech has now participated in this competition over the past two years (2010 and 2011) and intends to enter another competition vehicle in 2012. This paper reviews these efforts and discusses the key aspects of the design and development process, the related engineering considerations, and the learning process students have now gone through over those past two years. Student feedback and their assessment data are included to augment the understanding of the overall project outcomes. Lastly, a review of recommendations to other future possible Formula Hybrid ${ }^{\mathrm{TM}}$ competition participants is provided to faculty at other universities who may be interested in pursuing this as an alternative energy project with their students.
\end{abstract}

\section{1) Background of the Formula Hybrid ${ }^{\mathrm{TM}}$ International Competition}

The primary purpose of the paper is to discuss the overall approach, teaching opportunities that are especially related to energy storage and conversion, and learning benefits for the

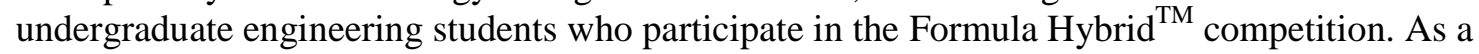
basis the author uses a two year review of his Lawrence Tech student teams who have participated in the competition. This paper is not intended to be one devoted to detailed discussion of the Formula Hybrid ${ }^{\mathrm{TM}}$ competition, nor does it discuss detailed technical elements of a successful hybrid design. But some discussion, however, of the competition is required to assist the reader who may not be familiar with the competition, or one who is interested in 
possibly considering having their students undertake the effort as a possible design project with their engineering students.

Hybrid electric vehicles with on-board electric energy storage, such as advanced lithium-ion batteries, are rapidly becoming a major area of research in the automotive industry with earlystage products now on the market. For the past several years numerous efforts and articles have been published discussing the overall technology development, electrification and hybridization of the automobile. Only a few of the hundreds of the possible discussions in the literature are cited in the reference section of this paper. ${ }^{1-10}$ Clearly, the technological migration towards the electrification of the automobile and the advent of the hybrid vehicle require engineering talent with the appropriate skills and background able to support these advancements in the automotive field. Even in the current depressed economy engineering students with knowledge and experience in this field are in high demand in automotive companies and their suppliers. ${ }^{11}$

To help meet these ends the Thayer school of Engineering at Dartmouth College established the Formula Hybrid ${ }^{\mathrm{TM}}$ competition in 2007 in collaboration with the Society of Automotive Engineers (SAE) and the Institute of Electrical and Electronics Engineers (IEEE). The explicit stated purposes of the Formula Hybrid ${ }^{\mathrm{TM}}$ competition are: ${ }^{12}$

1. To give engineering students the opportunity to work across disciplinary boundaries while engineering and developing an electric or hybrid-electric race car.

2. To encourage and promote the development of high-efficiency automotive drive trains.

While the more well-known Formula $\mathrm{SAE}^{\mathrm{TM}}$ competitions around the country and globally can have as many as 124 university teams competing at one event, the Formula Hybrid ${ }^{\mathrm{TM}}$ competition alternatively offers engineering students an excellent opportunity to participate in a highly challenging, but much smaller competition. For example in 2007 (the first year of the competition) six teams attended, in 2008 there were 14 teams, in 2009 twenty-two teams attended, in 2010 twenty-six teams competed and in 2011 there were twenty-five teams in attendance. $^{13}$

The competition, typically held during at the end of April and the first part of May each year, takes place at the New Hampshire Motor Speedway in Louden, New Hampshire. The competition consists of both static and dynamic activities where each participating team can earn points. Table 1 below lists the events and possible points earned for each stage of the competition.

Table 1: Formula Hybrid ${ }^{\mathrm{TM}}$ Competition Event Points. ${ }^{14}$

\begin{tabular}{|l|l|r|}
\hline Static Events & Presentation & 100 \\
\hline & Engineering Design & 200 \\
\hline Dynamic Events & Acceleration - Electric & 75 \\
\hline & Acceleration - Unrestricted & 75 \\
\hline & Autocross & 150 \\
\hline & Endurance & 400 \\
\hline & & 1000 \\
\hline
\end{tabular}


Prior to any team participating in any dynamic events each team's vehicle must undergo a series of rigorous physical reviews including a mechanical inspection, an electrical inspection, a tilt inspection, and a dynamic vehicle braking demonstration. No vehicle can compete unless it passes these inspections. In the event of inclement wet weather all vehicles must also be Rain Certified before running under wet track conditions. Details of these competitive events can be found in the Formula Hybrid ${ }^{\mathrm{TM}}$ competition rules. ${ }^{14}$ Unfortunately, over the past two years it was not uncommon for teams to fail one or more of these inspections, and as a result they were not allowed to compete in any dynamic events. This author learned from informal conversations with those inspection failing teams team's faculty advisors that these failures were usually a result of teams not arriving at the competition with a "race ready" vehicle.

\section{2) Lawrence Technological University's Involvement in the Competition}

Lawrence Technological University (Lawrence Tech) is located in the heart of the United States automotive capital just north of the City of Detroit in Southeast Michigan. Lawrence Tech has long been involved in the design, development, and building of alternative energy vehicles. Lawrence Tech's high performance hybrid electric diesel, a heavily modified Ford Taurus, won the National Championship in 2000 Tour de Sol. In 2008 Lawrence Tech designed and built a hydrogen fuel-cell powered $8 \mathrm{~kW}$ all-electric vehicle go-kart, called Element One, and competed in the Formula Zero completion in Rotterdam, The Netherlands. This kart was also featured in running test-track demonstrations at the National Hydrogen conference in 2009 in Columbia, South Carolina.

With the eventual conclusion of Formula Zero competition the group of Lawrence Tech students and faculty who were interested in alternative energy vehicles turned their attention to the Formula Hybrid ${ }^{\mathrm{TM}}$ competition. There were several reasons to transition to the hybrid competition.

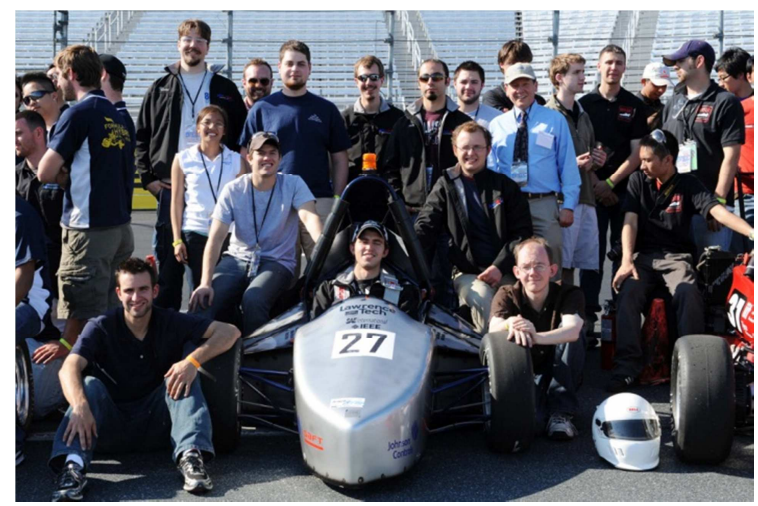

(a)

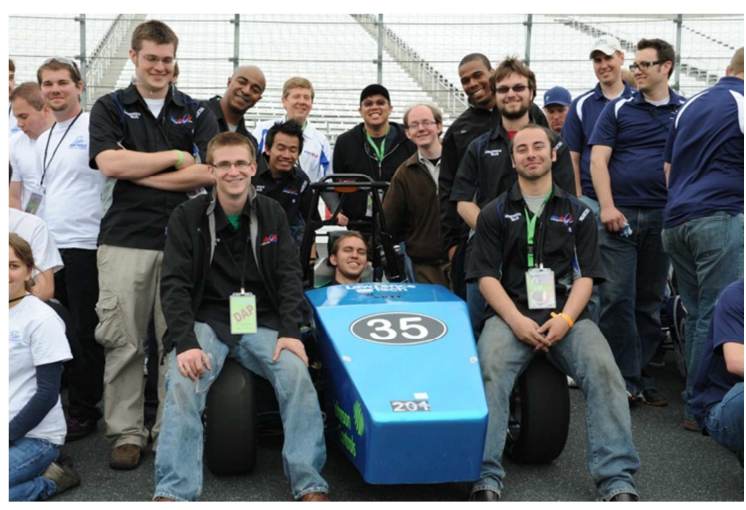

(b)

Figure 1: Photos of the Lawrence Technological University teams and vehicles for (a) 2010 and (b) 2011. These photos are from the Thayer School of Engineering at Dartmouth College, photos by Kathryn LoConte Lapierre. ${ }^{15,16}$

First, by 2008 it was becoming clearly evident that the challenges in implementing fuel cell technology (particularly hydrogen storage and distribution) would prevent its adoption into the automotive industry anytime soon. Also, the rapid growth of the hybrid development in the 
automotive field suggested that the Formula Hybrid ${ }^{\mathrm{TM}}$ competition was a much better fit for undergraduate engineering students to compete in design-and-build vehicle projects. The work done on the Element One vehicle, however, primarily laid the groundwork for Lawrence Tech to seriously consider entering the hybrid competition. Lawrence Tech has now participated in this competition over the past two years (2010 and 2011) and has now built another vehicle for the 2012 competition. The student academic demographics for the Lawrence Tech teams are not always easy to track because the club nature of the teams does not always allow for firm headcounts of each year's team. Unless a student is doing a Sr. Design project on the vehicle, team members are free to come and go on the team. Lawrence Tech does have a Technology degree program, but no students in the Technology program have participated in any of the Lawrence Tech Formula Hybrid ${ }^{\mathrm{TM}}$ competition teams. Table 2 documents the core group of students who have participated each year.

Table 2: Lawrence Tech Formula Hybrid ${ }^{\mathrm{TM}}$ team demographics

\begin{tabular}{|l|c|c|c|}
\hline & $2009-2010$ & $2010-2011$ & $2011-2012$ \\
\hline Mechanical Engineering & 6 & 7 & 9 \\
\hline Electrical Engineering & 4 & 6 & 6 \\
\hline Computer Science & 3 & 2 & 2 \\
\hline Other & 1 & 2 & - \\
\hline Female & 1 & 2 & 0 \\
\hline Male & 13 & 15 & 17 \\
\hline Seniors & 6 & 5 & 5 \\
\hline Total core team members & 14 & 17 & 17 \\
\hline
\end{tabular}

\section{3) Management Elements of the Formula Hybrid ${ }^{\mathrm{TM}}$ Competition Vehicle}

It is the strong option of this author that the two primary components of the Formula Hybrid ${ }^{\mathrm{TM}}$ competition are team management and technical expertise. Goff and Terpenny have documented their efforts within the contexts of their ME 4015 Engineering Design \& Project - Baja SAE®, course at Virginia Tech. ${ }^{17}$ These team advisors found that their primary challenge for their 20042005 Baja SAE® design competition was not one of mechanical engineering expertise, but one of team guidance and management. They reviewed the challenges of personalities and the variation of skill sets possessed by various team members and how they can contribute towards, or detract from, a successful team outcome, and how the team faculty advisor can facilitate addressing these efforts. These same opinions regarding the management challenges of Formula Hybrid $^{\mathrm{TM}}$ competition were informally communicated to this author by a competition judge in 2010. This judge essentially said that the Formula Hybrid ${ }^{\mathrm{TM}}$ competition was not so much a technical competition as it was a managerial competition. ${ }^{18}$ This author agrees to a point that the managerial components to the competition are real and, depending upon how they are addressed, will contribute to team success or failure just as much as poor design or technical skills. The technical challenges in this competition, however, are also significant due to the complexity of the vehicle and the integration level of interdisciplinary functions required to produce a functional vehicle. More is discussed about this later in this paper.

Schuster, Davol, and Mello review different approaches to advising Formula SAE, SAE Mini Baja, and ASME's Human Powered Vehicle student competition teams and compare the benefits 
and issues with each at California Polytechnic State University. ${ }^{19}$ They outline how these competitions typically operate on a one-year development cycle and their discussion correlates well with the Formula Hybrid ${ }^{\mathrm{TM}}$ competition. They correctly state that during the one year development cycle the team is expected to design, analyze, built, test, and prepare reports on the project. Most competitions require an all-new or mostly-new vehicle each year. The Lawrence Tech hybrid team timetable, however, differs from theirs. The Lawrence Tech timetable is listed below:

- Twelve to fifteen months before the competition: Team leaders for the following year's team are identified and the next year's competition team begins to recruit members

- All team leaders (project leader and sub-group leaders) for the for next year's competition are required to attend at least one Formula Hybrid ${ }^{\mathrm{TM}}$ competition event prior to their taking on a leadership role on the team.

- Current team travels to the competition in Loudon, New Hampshire along with future team leaders to compete.

- Eight to twelve months before the next year's competition:

○ The design rules for the competition are updated at this time so that only limited vehicle development is possible prior to this point.

○ The competition team's active fundraising begins with preparation of team presentations and documentation to establish sponsorships and team donors.

$\circ$ The competition vehicle design and analysis typically takes place. This includes development and testing of software to be implemented for this iteration of the vehicle.

- Four to ten months prior to the competition the procurement, fabrication, and assembly of the vehicle takes place. We strive for a rolling chassis by the end of December prior to the competition.

- One to three months before competition all rolling and powered vehicle testing and refinement of the vehicle take place.

- Mid-April before the competition the Blue Devil Motor Sports vehicle competition team unavailing take place with all the Lawrence Tech competition teams showing their work. This includes the Formula SAE, SAE Baja, and the SAE Aero Design teams, as well as the Formula Hybrid team. More will be discussed about this later in this paper.

- Late April or early May the competition takes place in Loudon, New Hampshire.

- After the competition a series of review meetings are held with current and future team members to assess and document the just completed results and future needed changes to vehicle activities and design.

This author agrees with Schuster, et al, regarding the role of the faculty advisor, and has found that to optimize the managerial learning experience for the students it is imperative to have an actively involved advisor. ${ }^{19}$ Lawrence Tech has found that the best results for the team, both for academic learning and for team performance at the competition, has been when the faculty advisor provides general guidance to the team, management input and technical advice in a supporting role only, and that the team principally be lead and directed by the students themselves. There is a fine line relating to actual and perceived ownership with student teams. If the faculty member is overly involved, directly manages the project, and "calls the shots", then the students will feel that it is the faculty advisor's project and not theirs. Under these conditions, when issues or problems arise (as they always do during any complex project) the students may 
feel that it is the faculty member's responsibility, and not theirs, to resolve and address the issues. They can and will defer responsibility to the advisor. This is not healthy for the project, nor is it a good environment for students to learn because their sense of project ownership is lost.

If the team faculty advisor is too distant from the project and not aware of the issues (either technical or managerial) then the team can drift, lose sight of the goals and fall apart. Poor or no faculty advisor input can also result in a serious lack of team structure or organization. This author observed several years ago a previous competition team (not in a hybrid team) intentionally created an impossible-to-manage team structure where no one was in charge! (This author stepped in and changed that one!) Clearly, without proper team structure even initially enthusiastic and highly motivated team members can later come to believe that no one owns the project and that no one cares about their success or failures. When no one is accountable to anyone then no one is responsible for anything.

The likelihood of a successful team throughout the project and the team's performance at the competition significantly improves if the students feel that their advisor(s) is genuinely interested in the project. ${ }^{19}$ This interest and caring, on the part of the advisor, can successfully be demonstrated in several ways, even when the faculty advisor allows the students to run their own project. For example, when the faculty advisor attends all major team project meetings and takes a role in showing how the students can negotiate their way through the university's bureaucracy, the advisor can significantly help the team and gain the respect and appreciation of the team members. The faculty advisor can also help with such matters as alumni relations for fund raising, external corporate sponsorships, campus security and off-ours facilities access, and safety training. The faculty advisor can also support the team by providing important advice on presentations, public relations, community awareness and the recruitment of new team members. It must be stated clearly, however, that advising and supporting a team takes significant time, and more so as the competition date nears. But such efforts by the faculty advisor directly benefit the team and can produce a significant level of appreciation from the team members towards the faculty advisor.

For the Lawrence Tech Formula Hybrid ${ }^{\mathrm{TM}}$ project we have learned that during the first phase of the project (the organizing the team in identifying critically needed team skill sets and in establishing team leadership and structure) the faculty advisor must work quite closely with the team. In some of these early critical stages the advisor may need to specifically define what should be a team's structure, based on available team student leadership, and the way their specific university's team support systems work. Because Lawrence Tech has now entered the Formula Hybrid $^{\mathrm{TM}}$ competition twice, with the 2012 competition in late April and early May being our third entry, we have found that initial faculty involvement is a critical step in the team's success. Once the team is launched and functional, however, the faculty advisor can and should quickly step aside and allow the team to operate as its own entity under its own leadership, with the faculty advisor's role rapidly transitioning to one of mentor and guild.

Two other areas that that faculty advisor can assist the team to keep the project on track are by helping the team establish clear and realistic milestones, and then reviewing with the team to make sure they meet those miles stones. There will be times when the advisor must also help resolve personality disputes and conflicts. Fortunately, the Lawrence Tech teams have not had 
many significant personal disputes! But this as with any project where people are working hard and trying to meet deadlines will have disagreements. When they have occurred the team looked for help, and this author had to assist in working things out between the disputing parties. On these few occasions other team members afterwards have thanked this author for helping settle things in an equitable manner and to help calm the anger.

At Lawrence Tech one of the most critical mile stones for all vehicle competition teams is the Blue Devil Motor Sports unveiling in mid-April. All competition team vehicles must be operational at this event. Failure to have a self-propelled operational vehicle at the unveiling can result in the team not being allowed to go to their respective competition. Prior to 2009 all Lawrence Tech SAE student competition teams were run as Senior Design Projects. Teams operated independently. Unfortunately, highly interested students in their first three academic years in the engineering program rarely had the opportunity to contribute in any significant way to the project. In the spring of 2009 Lawrence Tech began to transition our SAE vehicle competition teams into club groups, all under the overall guidance of the Blue Devil Motor Sports program. (The Lawrence Tech team mascot is the Blue Devil.) The club structure has allowed all of the motor sports team to share resources, technical expertise, and to develop a much greater camaraderie among themselves as Lawrence Tech students.

Under the Blue Devil Motor Sports club structure a spectrum of students are now free to participate in the SAE competition teams at Lawrence Tech, with some on more than one team. Common resources can be shared. We still allow senior engineering students to select specific aspects of the vehicle to do senior design projects on the vehicle. The benefit of this influx of all engineering students is that first, second and third year students can now become directly involved in the project, and sometimes take a leadership role. This is especially helpful for students who are new to the university, but highly interested in vehicle development, as they can now freely participate and begin to gain knowledge into the vehicle competition. There is, perhaps, a more significant component to this restructuring into the Blue Devil Motor Sports that relates to institutional memory. One of the challenges in the past with Lawrence Tech SAE competition teams was that when they were all senior-standing engineering student-driven, and when those senior engineering students graduated there was a forced re-startup of all of the knowledge and lessons learned for the next year's team. Even with reports and a few carry-over alumni who wanted to help next year's team, there was a significant loss in institutional memory regarding technical, managerial and fundraising knowledge gained from the previous years. The Blue Devil Motor Sports club structure now allows for retention of knowledge gained from year to year, and produces significant mentoring of under-classmen by upper-classmen on the teams.

\section{4) Unique and Critical Design Challenges of the Formula Hybrid ${ }^{\mathrm{TM}}$ Competition Vehicle}

The Formula Hybrid ${ }^{\mathrm{TM}}$ competition organizers at Dartmouth College have stated that the engineering challenges in designing and constructing a formula Hybrid car will likely involve all of the following areas. ${ }^{12}$

- High-Power Electronics, including motors, generators, controllers, and DC-DC converters

- Mechanical systems including suspension, steering, braking, chassis design, body design, and ergonomics 
- Race strategy and management

- Computerized systems control

- Data acquisition

- Internal combustion engines, including intake and exhaust systems, fuel management, camshaft profile design, and ignition systems

- Regenerative braking systems

- Project management

There are two basic system designs for hybrid vehicles. These are the series hybrid and the parallel hybrid systems. Each are illustrated in Figure 2 below. In the series hybrid system the internal combustion engine (ICE) is set to one optimal revolutions-per-minute cycle setting to optimize power and efficiency.

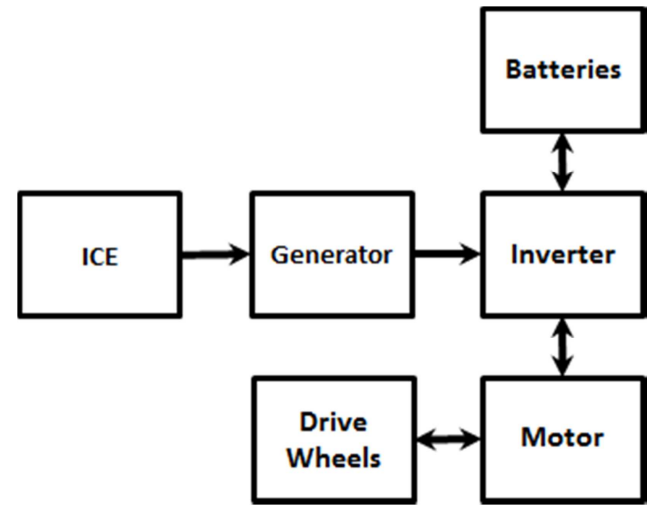

(a)

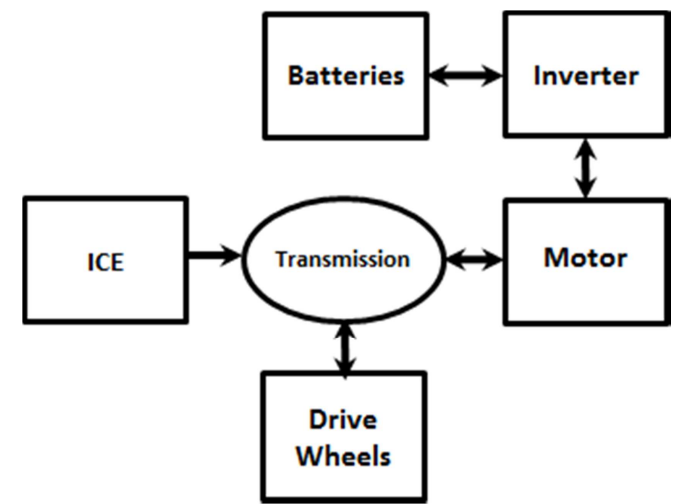

(b)

Figure 2: The basic possible configurations for the (a) series hybrid or (b) parallel hybrid power train configuration for a hybrid vehicle. Arrows pointing in both directions indicate possible regenerative braking capabilities.

The ICE is then coupled directly to an electric generator to charge on-board batteries or, depending upon the state of charge of the batteries, to provide electric power directly to the electric motor(s) drive train to propel the vehicle. A parallel hybrid has the ICE providing direct power to an electric generator or is capable of providing direct mechanical power to a drive train transmission to propel the vehicle. In the parallel configuration the motor serves also as a generator. Each of the two configurations has its advantages. ${ }^{21,22}$ Variations on these two designs are also possible. ${ }^{23}$ Important basic questions such as if the vehicle should be a series or parallel power system design has dramatic impact on how a team will proceed. These unique design features and alternative energy aspects of hybrid vehicles make this an ideal real-world senior design and university-based student club project. The Lawrence Tech team chose to employ a series hybrid design due to simplicity of design and to optimize the ICE performance.

Various authors have also discussed the challenges and issues with the design and building a Formula Hybrid vehicle. ${ }^{20,21}$ Lawrence Tech has been involved with the Formula SAE ${ }^{\circledR}$ competition since its inception. In fact, the first few Formula $S A E^{\circledR}$ competitions were originally held on the Lawrence Tech campus. Because of this long tradition, the mechanical system 
aspects of designing a Formula Hybrid vehicle have not been a significant challenge to our team. While there are common design elements to the more well-known Formula SAE ${ }^{\mathrm{TM}}$ car, the hybrid car requires much more electrical and computer interface design aspects to the overall project that are unique to hybrid vehicles. On-board energy storage in batteries, design of safe on-board electrical systems that are noise (electrical) and trouble free, and that can be externally charged, rengerative braking and electric generators and motors are all exclusive to hybrid car design.

The greater challenge for the Lawrence Tech teams has been the overall integration of these alternative drive train components of our vehicles. These particularly include the high-power electronics, generators, controllers, and computerized systems control. Our 2010 team tried to accomplish too many aspects of the design by software control. The lack of software development time and resources significantly put the team behind and as a result there was not enough time to adequately do system and drive testing prior to the competition. The 2011 team simplified these aspects by implementing better motor control, the removal of unnecessary electrical gadgetry and the combination of control boards for signal processing. This resulted in dramatic gains and helped the team to more effectively compete. The 2012 team has yet even further simplified software and combined electrical control systems to one main processor. Vehicle grounding for both high-voltage and low-voltage systems continues to be a concern.

The key design aspects for the 2012 hybrid vehicle are as follows:

Drive Configuration: Series

\section{Powertrain}

- Motors two Lynch Lem-200-D135 PM

- Peak Power92.0 hp @ 4,032 rpm

- Nominal Power 45.2 hp @ 4,032 rpm

- Rated Torque 58.8 ft.- lb. @ 4,032 rpm

- Peak Efficiency $90 \%$

- Rated Voltage/Current 96v/200a

- Motor Controller Evnetics, Soliton Jr. 9-340v/600a

Generator

- Internal Combustion Engine Briggs \& Stratton Animal Racing Engine

- Displacement 205cc

- Peak Power 7.5 hp @ 4,000 rpm

- Peak Torque $10 \mathrm{ft}$ - 1b. @ 4,000 rpm

- Motor Lynch Lem-200-D135 PM

- DC-DC Converter Zahn CH200 120F-SSU

- Generator Output (approx.) $9 \mathrm{kw} / 12 \mathrm{hp}$

Battery Powerplant

- Batteries Johnson Controls/Saft V16p

Chassis and Suspension

- Frame 4130 Chrome-Moly Steel Space Frame

- Wheels Keizer Forged Aluminum, 13 in. x 7 in.

- Tires Hoosier Racing Slick, 20.5 in. $x 10$ in. $x 7$ in. 


\section{5) Teaching and Learning Benefits of the Competition}

The benefit of using competition teams to assist in the education of engineering undergraduate students has been well documented. ${ }^{24-29}$ The Formula Hybrid ${ }^{\mathrm{TM}}$ competition is no different and as a result there are valuable teaching and learning opportunities for students, and faculty in this rapidly developing future growth area of the automotive field. Because so many benefits exist, only a few of the ones that have been observed within the participating students are listed here.

Soft skills:

- Collaborative team work

- Project management

- Organizing work activities as a routine

- Creating schedules, timelines and understanding the interdependency of work activities

- The purchasing and procurement of materials, hardware and components and understanding their lead-times to delivery

- Appreciation by students for interdisciplinary skill-sets outside of their major

- Listening and clear verbal communication with technical and non-technical individuals

- Working with the university's advancement office and other administrative staff

- Determination and drive to complete a common goal

- Selecting an optimal solution to a problem when several good options are available

- Visioning the possible end result when there is nothing there at the start of the project

- Meeting with potential sponsors and communicating the teams vision and needs

- Recruitment of future team members

- Trip and travel planning and routing

- Settling disputes and resolving conflict

- Developing an appreciation for sound decision making and wise leadership

- Reading and interpreting requirements, rules and regulations

- Understanding the consequences of failure

Technical and Engineering Skills:

- The integration of complex mechanical, electrical and software systems

- Complex CAD illustrations

- Simulation and modeling

- Fabrication processes such as welding, bending, cutting, joining and machining

- The selection, specification and performance of fasteners

- Corrosion prevention and paints

- Mold fabrication and fiberglass body construction

- Surface preparation and painting

- Static structures and dynamic systems

- Safety of both electrical and mechanical systems

- Tool use and maintenance

- System engineering

- Wire harness layout, assembly and electrical connector selection and assembly 
- Schematic layout and design

- Higher level and lower level software system design, development and testing

- Electrical circuit design, creation and testing in a larger non-lab bench setting

- Troubleshooting complex interconnected systems

- Controls and control dynamic responses to inputs

Several courses at Lawrence Tech are directly reinforced by this project. Because the project primarily involves the three main disciplines of mechanical engineering, electrical engineering, and computer science (or computer/software engineering), all of the core courses in each discipline provide team members the broad skills to successfully participate in this competition team such as their capstone senior design course(s). There are, however, a few key courses that any team faculty advisor should encourage members from each discipline to focus on (and possible collaboration with the instructing faculty member). For Mechanical Engineers these key courses include machine dynamics, automotive systems classes, and manufacturing processes. For electrical engineers courses in power electronics are critical. Unfortunately, many electrical engineering students do not see significant exposure to power electronics and rarely work with voltages above 5 volts, nor see electrical currents above milliamps. Computer engineering students need to be able to design processing boards and then develop embedded systems. Both electrical engineering and computer engineering students should be well versed in the CAN language, uses in automotive applications.

\section{6) Lawrence Tech Student Survey Feedback Regarding Their Team Participation}

Assessment is an important aspect of competition team activities within the College of Engineering at Lawrence Tech. A survey was circulated to Lawrence Tech students seeking out

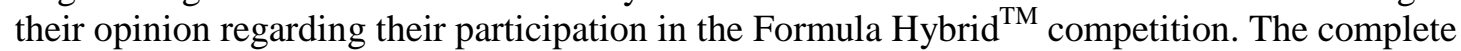
survey given to students can be found in the Appendix of this paper.

The survey consisted of five sections. These included some general background information about the respondent, why the respondent joined the Lawrence Tech Formula Hybrid ${ }^{\mathrm{TM}}$ competition team, their experiences while being part of the hybrid team, other comments, and information related to if the respondent had left the team. Many of these questions are related to internal use by the author and advisor of the team for the college of engineering at Lawrence Tech, so not every question or its responses are included in this paper. There are, however, some responses worth noting. At the time of this writing only about $17 \%$ of the voluntary responses had been received $(n=8)$. But enough responses had been received to be of some use and the data do shed light on the team member's experiences.

The data considered here show interesting aspects of current and former team member's perspective. The students generally wanted a formal collegiate competition experience; felt that the Formula Hybrid competition would be helpful in their career ambitions, but they also indicated that they had little to no knowledge of hybrid vehicle technology before joining the team. 
Written responses are overwhelmingly positive. The students directly saw the benefit from the hands-on experience and definitely felt that participating on the team and attending the competition was extremely valuable.

Here are averaged data and selected responses to some key questions on the survey. Student team member's comments are written in quotations and italic font:

A-1) I got involved in this work because I wanted a formal competition experience in college (on a scale of 1 to 5 ):

average response $=4.0$

A-3) I got involved in this research because I thought it could help me with my career ambitions (on a scale of 1 to 5 ):

average response $=4.7$

A-6) Prior to joining the Lawrence Tech - Formula Hybrid Competition Team I had a good understanding or previous experience with hybrid automobile technology (on a scale of 1 to 5):

average response $=1.9$

B-4) Seeing the hybrid vehicle run was a very important aspect of being part of the hybrid team (on a scale of 1 to 5):

average response $=5.0$

B-6) If you attended the competition in Loudon, New Hampshire, it was an important component of being part of the Lawrence Tech SAE Hybrid team, see also question B-29, (on a scale of 1 to $5)$ :

average response $=4.9$

B-25) Based on my experience with the Lawrence Tech- SAE Hybrid team I would like to pursue a career in this field or a closely related field (on a scale of 1 to 5):

average response $=4.9$

B-29) If you attended the competition in Loudon, New Hampshire, how was that attendance an important component of being part of the Lawrence Tech SAE Hybrid team (short written answer)?:

"This was critical for new team members to be a part of. Not only do they have a much, much better understanding about why things are done, it is a lot of fun to interact with the other teams." 
"It is not just important to see your own project completed, but to see the small victories and mistakes of other teams is equally so."

"Attending the event allows you to enjoy seeing all of your hard work come together. It also allows you to see competitor's ideas and learn from them. The biggest benefit is the feedback you receive from the judges on your designs, with that feedback you take home a much greater understanding."

“...good for networking, plus you become very close with everyone when the time is short left to finish"

C-1) Overall, is/was your involvement on the SAE Hybrid team a satisfying personal, academic, or professional experience? Why? (Short written answers)

"Yes, I was able to apply what I learned to all three."

"All three. I was able to learn to work with and around others to design a working vehicle. Seeing many systems working together is always a good experience. Professionally and academically, I was able to see how the electrical systems of cars were designed and implemented, and gained valuable experience in integrating sensors and debugging that I was able to apply to my work elsewhere."

"It was definitely a great experience all around. Before the team, I never knew the amount of work and time that needed to be put into a vehicle, not to mention the amount of knowledge needed to make the right decisions on design. What I saw on the team could not be taught in school. It's definitely something engineers should do for at least a year of the undergraduate career; it's eye-opening."

"Most exhausting and draining thing I ever did in my entire life and I would do it again in a heartbeat."

"My overall involvement on the SAE Hybrid team is a satisfying personal, academic, and professional experience."

"It was very satisfying because I grew as a leader as the years went on and my knowledge and understanding of how things worked also continued to grow throughout my experience. In the end it is what got me my job and taught me the skills to be successful within my job."

C-2) How is/was the SAE Hybrid team a worthy learning experience, and how did it help in your understanding of the technology? (Short written answers)

"It let me built what I learned. It let me experiment with designs and ideas. It gave me hands on experience." 
"I went from a 'conceptually vague' knowledge of the systems to almost encyclopedic knowledge of what components are/were/could be implemented in the vehicle, what technologies and standards were being used in the industry at present, and where it may go in the future."

"It was definitely a worthy learning experience. For one, we learned about the in and outs of the next generation of vehicles that will soon dominate the market. However, the learning curve was pretty steep considering we don't learn about most of the technology until late junior or senior year but it was nice because there isn't any sort of intimidation because my peers were the ones explaining information to me. Plus, no tests or exams."

"80\% of the learning experiences involved topics too specific to cover in a course, but gave purpose to the most generic lessons taught. It also gave good understanding as to the progression of technology and how fast it can occur (design improvement by iteration)"

"The SAE Hybrid team, including course work has broadened my understanding of race car, and hybrid technologies. It is a worthy learning experience."

"It is a worthy learning experience because it is all first-hand work and with troubleshooting and design you are forced to understand and grasp the concepts of the technology you are using."

C-3) Would you recommend that other Lawrence Tech students participate in similar types of competition teams? Why? (Short written answers)

"Yes, it provides hand- on experience, it will get you a job. It is a blast. The hard work is well worth it."

"There is no better way to learn than through a trial-by-fire. I believe that tests, finals, etc. could be replaced almost entirely with practical design projects (although this will never happen; the business types love the numbers)."

"I definitely recommend that other students participate in a competition team for at least one year. Just in that one year, you'll learn a lot about team work, yourself, others, and the technology."

"I think not everyone is cut out for competition teams due to the time impact, however I would say that anyone who is willing to put in the time benefits greatly and learns a great deal about dedication if nothing else. This becomes highly important in the professional world." (This comment is from a former team member who has now graduated and is working for one of the "big-three".)

"I would recommend to Lawrence Tech's students, that they participate in similar types of competition teams. These experiences will help improve study habits, networking skills, team work, the understanding of automotive technologies."

"I would recommend this experience because it is great on the resume and crucial to fully understanding the field of engineering." 
C-4) Please provide any other comments you think appropriate? (Short written answers)

"I did not know that you could go three solid days without sleep."

"At the time I was itching to contribute to a larger project in order to see implementations for the things that I had learned in class."

\section{7) Conclusions and Recommendations for Future Potential Formula Hybrid ${ }^{\mathrm{TM}}$ Competition Participants}

Lawrence Technological University student's experience with the Formula Hybrid ${ }^{\mathrm{TM}}$ competition has been overwhelmingly positive. We have seen it serve as an excellent, but very challenging, multi-disciplinary senior design project and also a club sport activity available for undergraduate engineering students from first-year to graduate students. The Formula Hybrid ${ }^{\mathrm{TM}}$ competition is now one of the staple competition teams within Lawrence Tech's Blue Devil Motor Sports club. It requires a well-integrated team with mechanical, electrical and computer engineering skills with each contributing at a high level. It is believed by this author that the Formula Hybrid $^{\mathrm{TM}}$ competition is the most challenging of all the SAE competition events due to the high level of advanced engineering system integration that is required.

Recommendations for future potential Formula Hybrid ${ }^{\mathrm{TM}}$ competition participants:

1) Select the correct faculty advisor (and the faculty advisor must be honest about his/her ability)

a. Future advisors must have time and energy to properly support the team.

b. The advisor should have a good knowledge of vehicle electrical and mechanical systems and well as energy storage systems such as batteries and ultracapacitors.

c. The advisor must enjoy working with students who are in the learning and discovery mode. Every day on this team will be a new experience for team members and part of that process will involve sometimes very basic and rudimentary questions that the advisor will need patience to answer.

2) Formulate a good relationship with the universities advancement office to help assure alumni funding and corporate sponsors are found, cultivated and developed. This can take time.

3) Spend extra time find good student team leadership with motivation, drive and endurance. This competition is a long-haul and sometimes very grueling. Student leadership that gives up will kill the team.

4) Recruit enthusiastic students. They want to learn the technology and providing an opportunity to do so will generate great enthusiasm.

5) Go to a competition in Loudon, New Hampshire the year before entering the competition. Take students along and get a feel for the events and the structure of the competition. This will be helpful for all in next year's team.

6) Review the rules carefully, and ask the completion organizers lots of questions. The have generally been very helpful and usually try to respond within a few days to key technical questions and issues. We have also found them to be very comprehensive in their answers. 
7) Make sure there is an adequate space, room or lab to build the vehicle, with adequate tools and a supporting machine shop.

8) Make sure there is adequate electrical technical expertise from the electrical engineering department and computer science department to help students get over technical jams and problems.

9) Plan the project activity early. Every team has the same number of days on the calendar before the event, but not all use their time wisely.

\section{References}

1) Nancy Gioia; Electrification of the Automobile; presentation to the University of Michigan Dearborn, March 16, 2010; Ford Motor Company

2) www.acea.be/news/news_detail/the_electrification_of_the_automobile/ ; The European Automobile Manufacturers Association website; last accessed January 1, 2012

3) Hal Turton; Sustainable global automobile transport in the 21st century: An integrated scenario analysis; Technological Forecasting \& Social Change, 73 (2006) 607-629

4) Boldea, I.; Automobile electrification trends: a review; International Aegean Conference on Electrical Machines and Power Electronics, 2007, 369 - 377

5) Marano, V.; Tulpule, P.; Gong, Q.; Martinez, A.; Midlam-Mohler, S.; Rizzoni, G.; Vehicle electrification: Implications on generation and distribution network , International Conference on Electrical Machines and Systems (ICEMS), 2011, 1 - 6

6) Shaik Amjad, S. Neelakrishnan, R. Rudramoorthy; Review of design considerations and technological challenges for successful development and deployment of plug-in hybrid electric vehicles; Renewable and Sustainable Energy Reviews, 14 (2010) 1104-1110

7) Fabian Kley, Christian Lerch, David Dallinger; New business models for electric cars-A holistic approach; Energy Policy, 39 (2011) 3392-3403

8) Adam Same, Alex Stipe, David Grossman, Jae Wan Park; A study on optimization of hybrid drive train using Advanced Vehicle Simulator (ADVISOR); Journal of Power Sources 195 (2010) 6954-6963

9) E. D. Tate, Michael O. Harpster and Peter J. Savagian; The Electrification of the Automobile: From Conventional Hybrid, to Plug-in Hybrids, to Extended-Range Electric Vehicles; SAE Technical Paper Series 2008-010458, from Advanced Hybrid Vehicle Powertrain, 2008 (SP-2153)

10) Grincourt, Y.; The electrification of the automobile and its impact on the electric grid in Canada; 26 September 2011, EV2011Conference, Toronto, Canada

11) Personal communication with Peg Pierce, Director of Career Services, Lawrence Technological University, and with various companies at recent Lawrence Tech Job Fairs

12) www.formula-hybrid.org/about.php ; last accessed January 1, 2012

13) www.formula-hybrid.org/history/index.php ; last accessed January 1, 2012

14) www.formula-hybrid.org/pdf/Formula-Hybrid-2012-Rules.pdf ; Formula Hybrid rules

15) www.flickr.com/photos/thayerschool/sets/72157623887303883/ ; last accessed January 1, 2012

16) www.flickr.com/photos/thayerschool/sets/72157626513266429/ ; last accessed January 1, 2012

17) Goff, R. and Terpenny, J; Capstone Design, Mechanical Engineering Project or Personnel Management challenge?; ASEE Annual Conference and Convention Proceedings, 2006, paper \#1676

18) Personal verbal communication between the author and one of the Formula Hybrid ${ }^{\mathrm{TM}}$ competition judges during the 2010 competition event at Loudon, New Hampshire

19) Schuster, P., Davol, A., Mello, J.; Student Competitions - Benefits and Challenges, ASEE Annual Conference and Convention Proceedings, 2006, paper \#1835

20) Chang, I, et al; Designing and manufacturing of Formula SAE-Hybrid racecar for a new engineering education program, 2010 IEEE Vehicle Power and Propulsion Conference,

21) Benson, K.W., et al; The hybridization of a Formula race car; 2005 IEEE Vehicle Power and Propulsion, 2005 IEEE Conference

22) Emadi, A., et al; Topological Overview of Hybrid Electric and Fuel Cell Vehicular Power System Architectures and Configurations, 2005 IEEE Transactions on Vehicular Technology, 54 (3), 763 - 770 
23) White D., McKisson J., Barott, W.; An Innovative hybrid-electrical drive train concept and student project; 2007 ASEE Annual Conference and Convention Proceedings, paper \#429

24) Sepahpour, B., Chang, S.R.; Valuable Lessons from the Successes and Failures of Teams of Engineering Students; 2003 ASEE Annual Conference, Paper \# 2005-2481.

25) Wankat, P.C.; Undergraduate Student Competitions; Journal of Engineering Education, 94 (3): 343-7

26) Reimer, D., Ali, A., Abro, S.R., Relationship, between student competitive activities and the entrepreneurial mindset; 2011 ASEE Annual Conference and Convention Proceedings, paper \#19

27) Dutson, A., et al; A Review of Literature on Teaching Engineering Design Through Project-Oriented Capstone Courses; Journal of Engineering Education, 86 (1): 17-28

28) Lueptonw, R., Student Participation, Faculty Involvement, and Costs in the NGV Challenge - A Large-Scale Automotive Design Project; Journal of Engineering Education, 83 (2): 182-185

29) Carroll, D.R., Hirtz, P.D., Teaching Multi-Disciplinary Design: Solar Car Design, Journal of Engineering Education, 91 (2): 245-248 


\section{APPENDIX}

\section{Lawrence Tech - Formula Hybrid Team Student Survey, January 2012}

i) I joined the Lawrence Tech - Formula Hybrid Competition Team in month year -

ii) When I joined the group I was a:

Freshman

Sophomore

Junior

Senior

Grad Student

iii) My primary role on the Lawrence Tech Hybrid team was as:

iv) Are you still on the team?:

Yes

No: I left in (month) (year)

v) If you left the group, why did you do so (pick one only):

- graduated

- outside work opportunity that created a time conflict

- class load at school

- team activity was not a good fit for me

A) Why you wanted to join the Lawrence Tech- Formula Hybrid Competition Team.

Please answer each question by placing only one of the simple following point scale values after each question

Strongly disagree - 1

Disagree -2

No opinion -3

Agree - 4

Strongly agree -5

A-1) I got involved in this work because I wanted a formal competition experience in college (on a scale of 1 to 5):

A-2) I got involved in this team because I was very much interested in hybrid automobiles (on a scale of 1 to 5):

A-3) I got involved in this research because I thought it could help me with my career ambitions (on a scale of 1 to 5):

A-4) I got involved in this team because I thought it could help me if I went on to graduate school (on a scale of 1 to 5):

A-5) I got involved with this team because a friend invited me to join (on a scale of 1 to 5):

A-6) Prior to joining the Lawrence Tech - Formula Hybrid Competition Team I had a good understanding or previous experience with hybrid automobile technology (on a scale of 1 to 5):

A-7) Provide any other comments about why you joined the Lawrence Tech- Formula Hybrid Competition Team you think are pertinent (short answer):

B) Your experiences while being part of the Lawrence Tech-SAE Hybrid team.

Please answer each question by placing only one of the simple following point scale values after each question 
Strongly disagree -1

Disagree -2

No opinion -3

Agree - 4

Strongly agree -5

B-1) Once I got involved with the team I understood the primary objectives and mission of the hybrid team (on a scale of 1 to 5 ):

B-2) I learned a great deal about the technical elements of hybrid vehicles while working in the group (on a scale of 1 to 5$)$ :

B-3) The opportunity to be part of designing, building and supporting a hybrid vehicle was an important benefit of being a member of the group (on a scale of 1 to 5, and then list which one of these three aspects you feel was the most important?):

B-4) Seeing the hybrid vehicle run was a very important aspect of being part of the hybrid team (on a scale of 1 to 5):

B-5) I attended the following number of competitions in Loudon, New Hampshire (provide a number from zero to two based on the times you attended):

B-6) If you attended the competition in Loudon, New Hampshire, it was an important component of being part of the Lawrence Tech SAE Hybrid team, see also question B-29, (on a scale of 1 to 5):

B-7) Attending the Loudon, New Hampshire was a positive activity (on a scale of 1 to 5 and include a short statement as to why):

B-8) Regular team meetings are/were an important part of being a member of the team (on a scale of 1 to 5):

B-9) While being a member of the team I believe my input is/was valued and helped contribute to the team's success (on a scale of 1 to 5 ):

B-10) Based on my experiences on the team I see how important collaborative team work is for the success of such a competition team beyond what I would have learned in regular classes (on a scale of 1 to 5):

B-11) I gained valuable insights on what it takes to manage and lead such a team beyond what I would have learned in regular classes (on a scale of 1 to 5):

B-12) Based on my experience with the Lawrence Tech-SAE Hybrid team I believe that I understand what constitutes the basic elements of vehicle design and development better than what I would have learned in regular classes (on a scale of 1 to 5):

B-13) Based on my experience with the Lawrence Tech-SAE Hybrid team my capabilities of defining, organizing and coordinating multiple activities have significantly improved beyond what I would have learned in regular classes (on a scale of 1 to 5):

B-14) Based on my experience with the Lawrence Tech-SAE Hybrid team my ability to identify, formulate, and solve engineering problems has significantly improved beyond what I would have learned in regular classes (on a scale of 1 to 5$)$ :

B-15) Based on the presentations we had to give to various outside groups and to the other members of our team my ability to communicate effectively has significantly improved beyond what I would have developed in regular classes (on a scale of 1 to 5): 
B-16) Based on my experience with the Lawrence Tech-SAE Hybrid team my ability to apply knowledge of mathematics, science, and engineering elements to problems has significantly improved beyond what I would have learned in regular classes (on a scale of 1 to 5):

B-17) Based on my research experience with the Lawrence Tech- SAE Hybrid team my ability to design a system, component, or process to meet desired needs has significantly improved beyond what I would have learned in regular classes (on a scale of 1 to 5):

B-18) Based on my research experience with the Lawrence Tech- SAE Hybrid team my understanding of professional and ethical responsibility has significantly improved beyond what I would have learned in regular classes (on a scale of 1 to 5):

B-19) Based on my research experience with the Lawrence Tech- SAE Hybrid team my ability to use the techniques, skills, and modern engineering tools necessary for engineering practices has significantly improved beyond what I would have learned in regular classes (on a scale of 1 to 5):

B-20) I met and got to work with people in the SAE Hybrid team that I did not know before joining the team (on a scale of 1 to 5 ):

B-21) I became friends with most, if not all, of those that I worked with on the SAE Hybrid team (on a scale of 1 to $5)$ :

B-22) Participating on the Lawrence Tech- SAE Hybrid team was a positive addition to my educational experience at Lawrence Tech (on a scale of 1 to 5):

B-23) Participating on the Lawrence Tech- SAE Hybrid team took more time than I anticipated (on a scale of 1 to 5, and then provide a short answer to help explain):

B-24) I believe all students at Lawrence Tech should have an opportunity to participate in some type of competition team experience at Lawrence Tech (on a scale of 1 to 5):

B-25) Based on my experience with the Lawrence Tech- SAE Hybrid team I would like to pursue a career in this field or a closely related field (on a scale of 1 to 5):

B-26) I believe that our faculty advisor adequately supported the Lawrence Tech - SAE Hybrid team, (on a scale of 1 to 5). Please be very honest!:

B-27) I believe that the College of Engineering at Lawrence Tech adequately supported the Lawrence Tech - SAE Hybrid team (on a scale of 1 to 5):

B-28) I believe that the Advancement Office at Lawrence Tech adequately supported the Lawrence Tech - SAE Hybrid team (on a scale of 1 to 5):

B-29) If you attended the competition in Loudon, New Hampshire, how was that attendance an important component of being part of the Lawrence Tech SAE Hybrid team (short written answer)?:

B-30) How could your team advisor, the College of Engineering or the Advancement Office have improved their support for the Lawrence Tech - SAE Hybrid team (short written answer)?

B-31) Please provide any additional comments you believe are important or beneficial about your participation on the Lawrence Tech - SAE Hybrid team (short written answer):

C) Other additional comments/observations:

C-1) Overall, is/was your involvement on the SAE Hybrid team a satisfying personal, academic, or professional experience? Why? (Short written answers) 
C-2) How is/was the SAE Hybrid team a worthy learning experience, and how did it help in your understanding of the technology? (Short written answers)

C-3) Would you recommend that other Lawrence Tech students participate in similar types of competition teams? Why? (Short written answers)

C-4) Please provide any other comments you think appropriate? (Short written answers)

D) Please answer the following if you have since left the Lawrence Tech- SAE Hybrid team. Please do not answer if you are still part of the group.

Please respond to each statement .

D-1) Since my leaving the Lawrence Tech- SAE Hybrid team I am no longer a student at Lawrence Tech:

Yes - graduated and not at Lawrence Tech any longer

No - I'm still there

D-2) I have been employed since leaving the Lawrence Tech- SAE Hybrid team:

Yes

No

Please answer each of the next questions by placing only one of the simple following point scale values after each question

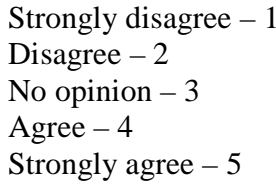

D-3) My current employment (or recent) is (was) directly related to the work done by the Lawrence Tech- SAE Hybrid team (on a scale of 1 to 5):

D-4) My experience with the Lawrence Tech- SAE Hybrid team significantly contributed to my ability to secure my current (or recent) job (on a scale of 1 to 5):

D-5) My experience with the Lawrence Tech- SAE Hybrid team has directly benefited me in my current (or recent) employment situation (on a scale of 1 to 5):

D-6) Based on my experiences and what I have learned in the Lawrence Tech- SAE Hybrid team I believe that I am now better equipped to undertake what constitutes successful research efforts in my place of employment or graduate school (on a scale of 1 to 5):

D-7) Based on my experience with the Lawrence Tech- SAE Hybrid team, and now with my perspective in industry, I believe industry would benefit from employing students who have had some level of recent competition team experience (on a scale of 1 to 5):

D-8) Based on my experience with the Lawrence Tech- SAE Hybrid team, and now with my perspective in industry, I would tend to hire recent undergraduate students who have had some level of undergraduate competition team experience (on a scale of 1 to 5):

D-9) Based on my experience with the Lawrence Tech- SAE Hybrid team, and now with my perspective in industry, I definitely recognize the need for, and an ability to engage in life-long learning that extends beyond my academic degree (on a scale of 1 to 5):

D-10) Please provide any additional comments about your former experiences with the Lawrence Tech- SAE Hybrid team? (Short written answer): 